\title{
Past, Present and Future Directions in the Study of the History of Retailing
}

\author{
Andrew Alexander \\ School of Management, University of Surrey, Guildford, Surrey, UK
}

This is a revised version of the plenary paper presented at the CHORD Conference, University of Wolverhampton, $9^{\text {th }}$ September, 2009.

\begin{abstract}
Purpose - The purpose of this paper is to provide an evaluation of some of the recent progress in the study of the history of retailing, with particular reference to analyses of the British retail market during the 20th Century.

Design/methodology/approach - Three themes are addressed, each of which has significant potential to enhance our understanding of the historical development of the retail sector. The paper considers both conceptual and empirical contributions to the discussion on the history of retailing, with particular reference to the business management literature. The approach involves a review of recently published literature.
\end{abstract}

Findings - Whilst there have been a number of important additions of late to the retail history literature, considerable scope remains for engagement with, and contribution to, the theory building taking within business management.

Practical Implications - The author identifies some of the lacunae within research on the history of retailing.

Originality/value - Illustrates some of the ways in which the study of retailing history can be productively linked with debates within contemporary studies of business management.

Keywords - Retail history, Retail innovation, Retail supply chain, Consumption. Paper Type - Viewpoint.

\section{Introduction}

The invitation to comment upon progress in the study of the history of retailing at the 2009 CHORD Conference was both welcome and timely; the 2009 event marking the tenth anniversary of this annual conference. The brief given was to focus on the past, present and future of retail history from the disciplinary perspective of business management, and more particularly from that of retail management. Whilst the study of retail history is inherently multi-disciplinary, in the discussion that follows I pay particular attention to contributions that fall within my disciplinary remit.

In the main part of the paper I discuss three themes relating to the study of the history of retailing which, I consider, offer significant potential to enhance our understanding: first, the acknowledgement of the mutual implications of the 'economic' and 'cultural' in studies of retailing and consumption, and its relevance to work on retail history; second, the historical analysis of the wider retail supply chain; third, the need for a more thorough consideration of the retail innovation process. Some of these themes have been addressed previously, including in the plenary papers given at the first CHORD Conference (Benson, 1999; Shaw, 1999). In developing my discussion, I reflect upon some of the arguments made at that meeting, and evaluate the progress made in relation to each theme in the ensuing period. In addressing only three themes 
I am, of course, being selective; there are a number of other areas in which further research would pay a good dividend.

The detailed examples that I draw upon in support of the discussion focus mainly upon the development of fixed-shop retailing in Britain during the 20th Century, and particularly the supermarket format. Concern for more recent aspects of historical development prevails within the retail management literature to a greater extent than within many of the other literatures that contribute to the study of retail history, and the role of historical method is seen as to contribute to debates on the "fundamental nature and problems of the retail sector" (Alexander, 1997, p. 398). Whilst limiting my focus in this way, many of the arguments that I advance are relevant to those whose interests lie in exploring the history of retailing in different time periods and locations, and at differing geographical scales.

\section{Linking economic and cultural interpretations}

Across many disciplines of the humanities and social sciences, the rapid development of work on the theme of consumption, particularly from the 1980s, has stimulated interest in the history of retailing, and the academic study of the retail sector more generally. One beneficial aspect of the concerted attention given to issues of consumption has been the heightened awareness of the interactions between the 'economic' and 'cultural'. In geography we have seen, over the last decade or so, the enriching of the so-called new retail geography with its explicit acknowledgement of the rather arbitrary nature of these categories and of their mutual implications (Lowe and Wrigley, 1996, p. 29). It would appear that similar conclusions have emerged among historians working on consumption. As Strasser (2002, p. 761) observed, "the realm of consumption is a domain where dyads merge: an arena of both money and love, both buying and making", and she remarks upon the increasing sophistication among historians in negotiating these dyads. In relation to consumer research, including within the discipline of marketing, Arnould and Thompson (2005, p. 868) identify a body of work that addresses the socio-cultural, experiential, symbolic and ideological aspects of consumption, and which they label Consumer Culture Theory (CCT). Importantly, they tackle what they consider to be a misconception that such research is of generally limited managerial relevance, and argue that "the dominant thrust of CCT research addresses issues that are highly relevant to social scientific, managerial and public policy constituencies" (Arnould and Thompson, 2005, p. 870).

The importance of the interplay between the economic and cultural became clear in my own work as part of a wider study into the development of the supermarket in early post-war Britain. An exploration of shoppers' reactions to the format revealed the challenges faced by many supermarket retailers in becoming a true 'one-stop shop' for food during the latter years of the 1950s and the early 1960s. This was often the result of comparatively weak performance in the fresh fruit and vegetables and particularly the fresh meat categories. As a consequence, the early supermarket proposition was frequently subject to selective adoption by consumers; in this case related to product categories (see Alexander et al., 2008).

Further analysis led to the conclusion that the problem was at once both economic and cultural. Selective adoption reflected shoppers' perceptions of the product quality, and thus the value for money, of the fresh foods sold by many self-service stores and 
supermarkets. It also reflected the centrality of shopping among housewives' tasks, it was mostly women doing the food shopping, and the construction of notions of competence in this regard. Consequently, heightened perceptions of social and psychological risk were evident in any switching to the new supermarket format for these types of goods, and threatened to temporarily slow the supermarket's onward march (for further details, see Alexander et al., 2008). The post-war decades saw concerted efforts by supermarket retailers and others to reconfigure supply chains to account for the revised quantity and style of selling going on in the stores. They also witnessed the commissioning of detailed market research designed to provide a better understanding of shoppers' perceptions of the supermarket, and the use by some retailers of revised methods of customer service and promotion to sell fresh foods.

The perspectives outlined at the start of this section of the paper can help limit any tendency toward the artificial polarization of the historical analysis of retailing between economic and cultural interpretations (Shaw, 1999). Teasing out the sometimes complex interactions that exist is not easy, but the potential benefits to our understanding of the patterns and processes of historical changes occurring within the retail sector, and of the practices of those working within it, justify the efforts required.

\section{Exploring the retail supply chain}

At early CHORD meetings, and elsewhere, discussions highlighted the lack of detailed analyses of the historical development of the retail supply chain. This deficiency has been perhaps more pronounced in relation to studies of retailing in the late modern period, as opposed to the early modern, despite a number of significant early business histories of vertically integrated firms in trades including men's tailoring, footwear and grocery and provisions. However, several recent studies have given much needed attention to the retail supply chain, including in relation to development of the wholesale sector.

Godley and Williams (2009), for example, reveal how Sainsbury's, a retailer with considerably more experience in the sale of provisions than many of its post-war supermarket rivals, sought to instigate and control collaborative relationships in the British poultry industry during the 1950s and 1960s. They explain how this British model of retailer control and coordination in the supply chain differed from that typical in the US, and argue that the ability to manage collaborative relationships in the supply chain would continue to be an important underpinning to Sainsbury's success during the 1980s. Turning to the wholesale sector, the work of Quinn and Sparks (2007) provides a comparison of the development of modern grocery wholesaling from the 1930s in Britain and Ireland. They observe a broadly similar evolutionary pattern in both markets focussed around phases of structural reinforcement, tension, fracture, reconfiguration and consolidation.

The relevance of Quinn and Sparks' work stretches beyond its inherent value in revealing changes in the organization of the wholesale sector itself. In particular, it focuses our attention upon matters of channel design and the power relations between manufacturers, wholesalers and retailers, including the very many small-scale and independent retail firms. Whilst, in general terms, the wholesale sector faced increasing pressure during the inter-war years, the pattern was not uniform across the 
trades. For example, Jefferys (1954) provides a brief discussion of the relationship between an increasingly important wholesaling function and the growing number of small-scale specialist retailers of made up goods in the women's wear trade in interwar Britain, in which the wholesaler could represent an important source of credit and other assistance.

Studying channel organization and the relations between channel members also affords us the opportunity to explore the development of new business forms that emerge. In the grocery trade, for example, we see the formation of wholesaler voluntary groups and retailer buying groups in Britain from the mid 1950s. The activities of retailers in these groups remain largely untouched in terms of the historical analysis of retailing, in contrast to studies of some other European markets. More work on such new forms of organization will further help to address the call made by Benson (1999) at the first CHORD conference for additional attention to be given to the small-scale retailer. Through this we can enhance our understanding of the opportunities for, and pressures upon, small-scale and independent retailers, and their differing practices to those of their large-scale and corporate competitors.

\section{Analyzing the retail innovation process}

It is perhaps self-evident that the theme of retail innovation is an important one within the study of the history of retailing. After all, one of the enduring debates revolves around the timing, nature and extent of any discontinuity between early modern and late modern retail systems. Similarly, retail historians have drawn upon attempts within the retail marketing literature to identify a general theory of retail institutional change. The best known of these is the Wheel of Retailing, recently described by a critic of the theory as being "... seductive, easily teachable, and frequently the focus of academic debates..." (Savitt, 2009, p. 192).

Notwithstanding the above, developments in the conceptualization and theorization of innovation have remained surprisingly scarce within the recent retail history literature, and despite the fundamental significance of innovation to retail firms' competitive advantage. In particular, insufficient consideration has been given to the processes of knowledge creation and learning within the firm, and to knowledge transfer both between firms and places; processes that have received more comprehensive consideration in the wider business history literature (on retail history see Alexander et al., 2005; Savitt, 1999). Historical analyses of retail change would benefit from a deeper engagement with the lively debate taking place within the retail management literature and elsewhere on this theme (see Currah and Wrigley 2004; Nonaka et al., 2007), and could contribute an important historical perspective to current attempts at theory building (for an example of this see Kjellberg and Helgesson, 2007).

Innovation can require the retail firm to work more closely and in new ways with suppliers, and a network perspective is occasionally employed within the literature to illustrate and account for the firm's search for external value-creating resources. We can consider retail format innovations such as the supermarket in this way. Retailers adopting this format engaged in new working arrangements not only with the producers and distributors of the goods sold, but with a range of other businesses and institutions. Firms such as National Cash Register offered new technologies that became of vital importance to the successful operation of supermarkets (Cortada, 
2004), and established advisory bureaux providing practical advice for retailers considering adopting the new format. Similarly, packaging manufacturers, like British Cellophane, were developing new types of film and bags for the presentation and preservation of a widening array of goods sold by self-service methods. We could add to this list the suppliers of the supermarket trolley (or shopping cart), itself a critical innovation in the development of the supermarket (Grandclément, 2009).

We also need to consider in more detail the role of the shopper in the retail innovation process, and to build upon the few existing historical studies of this (see Alexander et $a l ., 2009)$. Research in various disciplines identifies the ways in which the capacity and willingness of consumers -broadly defined- to commit to an innovation constitutes part of the context which determines its success or failure. Studies of innovation in the service industries explore the significance of adding customer knowhow to the formalization of innovation in service-based relationships (Gallouj and Weinstein, 1997), whilst the influential debate on the service-dominant logic (S-D logic) in marketing is significant in this context because of the centrality it affords the customer (Vargo and Lusch, 2004; 2008; Lusch et al., 2007). In S-D logic, "value is always co-created with and determined by the customer" (Lusch et al., 2007, p. 8). This gives added relevance to attempts to identify those factors that determine shoppers' willingness and ability to co-create, and the risks attendant in such activity. It has also led to attempts to extend the original propositions of S-D logic to more comprehensively acknowledge the contextual, experiential, and meaning-laden nature of value through consumption (Arnould et al., 2006; Vargo and Lusch, 2008). Such attempts further illustrate the importance of exploring the links between economic and cultural interpretations of the causes of retail change, and as such connect back to the first theme of this paper.

\section{Concluding comments}

In this brief paper I have discussed three themes that have the potential to enhance the study of the history of retailing, and reviewed some of the progress made in each. The first of these themes relates to the importance of avoiding the artificial polarization of the historical analysis of retailing between economic and cultural interpretations, and of exploring the implications of the interactions between economic and cultural forces for the historical development of the sector. I consider that we have a stronger conceptual apparatus at our disposal now to assist us, but that there need to be further empirical studies pursuing this agenda. The second theme relates to the study of the wider retail supply chain. Here we have seen some useful recent additions to the literature on the historical development of retailing. If we reflect upon the economic importance of the supply chain function to retailing, then it is to be hoped that these studies represent the vanguard of a new series of such research. The third theme, the conceptualization and theorization of the retail innovation process, has seen perhaps least progress made of late within the literature on retail history. This is surprising given the obvious value of the historical comparative to such theory building. Here we would benefit from a more thorough engagement with the lively debate taking place within the retail management literature and elsewhere.

\section{References}

Alexander, A., Shaw, G., and Curth, L. (2005), "Promoting retail innovation: 
knowledge flows during the emergence of self-service and supermarket retailing in Britain", Environment and Planning A, Vol. 37 No. 5, pp. 805-821.

Alexander, A., Phillips, S. and Shaw, G. (2008), "Retail innovation and shopping practices: consumers' reactions to self-service retailing", Environment and Planning A, Vol. 40 No. 9, pp. 2204-2221.

Alexander, A., Nell, D., Bailey, A.R. and Shaw, G. (2009), "The co-creation of a retail innovation: shoppers and the early supermarket in Britain", Enterprise and Society, Vol. 10 No. 3, pp. 529-558.

Alexander, N. (1997), "Objects in the rearview mirror may appear closer than they are", The International Review of Retail, Distribution and Consumer Research, Vol. 7 No. 4, pp. 383-403.

Arnould, E.J. and Thompson, C.J. (2005), "Consumer Culture Theory (CCT): twenty years of research", Journal of Consumer Research, Vol. 31 No. 4, pp. 868882.

Arnould, E.J., Price, L.L. and Malshe, A. (2006), “Toward a cultural resourcebased theory of the customer", in Lusch R. F. and Vargo S. L. (Ed.), The Service-Dominant Logic of Marketing. Dialog, Debates and Directions, M.E. Sharp, London, pp. 91-104.

Benson, J. (1999), "What is wrong with retail history?", paper presented at the CHORD Conference, 'New Directions in the History of Retailing and Distribution', 10 September, University of Wolverhampton, UK.

Cortada, J.W. (2004), The Digital Hand: How Computers Changed the Work of American Manufacturing, Transportation, and Retail Industries, Oxford University Press, New York, NY.

Currah, A. and Wrigley, N. (2004), "Networks of organizational learning and adaptation in retail TNCs", Global Networks: A Journal of Transnational Affairs, Vol. 4 No. 1, pp. 1-23.

Gallouj, F. and Weinstein, O. (1997), "Innovation in Services", Research Policy, Vol. 26 No. 4 -5, pp. 537-556.

Godley, A.C. and Williams, B. (2009), "The chicken, the factory farm, and the supermarket: the emergence of the modern poultry industry in Britain", in Belasco, W. and Horowitz, R. (Ed.), Food Chains. From Farmyard to Shopping Cart, University of Pennsylvania Press, Philadelphia, PA, pp. 47-61.

Grandclément, C. (2009), "Wheeling one's groceries around the store: the invention of the shopping cart, 1936-1953", in Belasco, W. and Horowitz, R. (Ed.), Food Chains. From Farmyard to Shopping Cart, University of Pennsylvania Press, Philadelphia, PA, pp. 233-251.

Jefferys, J.B. (1954), Retail Trading in Britain 1850-1950, Cambridge University Press, Cambridge, UK.

Kjellberg, H. and Helgesson, C-F. (2007), "The mode of exchange and shaping of markets: distributor influence in the Swedish post-war food industry", Industrial Marketing Management, Vol. 36 No. 7, pp. 861-878.

Lowe, M. and Wrigley, N. (1996), "Towards the new retail geography", in Wrigley, N. and Lowe, M. (Ed.) Retailing, Consumption and Capital. Towards the New Retail Geography, Longman, Harlow, UK, pp. 3-30.

Lusch, R.F., Vargo, S.L. and O'Brien, M. (2007), "Competing through service: insights from service-dominant logic", Journal of Retailing, Vol. 83 No. 2, pp. 5-18.

Nonaka, I., Peltokorpi, V. and Senoo, D. (2007), "Knowledge creation in a Japanese 
convenience store chain: the case of Seven-Eleven Japan", in Bryson, J.R and Daniels, P.W. (Ed.), The Handbook of Service Industries, Edward Elgar Publishing, Cheltenham, UK, pp. 355-376.

Quinn, J. and Sparks, L. (2007), "The evolution of grocery wholesaling and grocery wholesalers in Ireland and Britain since the 1930s", International Review of Retail, Distribution and Consumer Research, Vol. 17 No. 4, pp. 391-411.

Savitt, R. (1999), "Innovation in American retailing, 1919-39: improving inventory management", The International Review of Retail, Distribution and Consumer Research, Vol. 9 No. 3, pp. 307-320.

Savitt, R. (2009), "Teaching and studying marketing history: a personal journey" Journal of Historical Research in Marketing, Vol. 1 No. 2, pp. 189-199.

Shaw, G. (1999), "Themes in retail history: traditional pathways and new directions", CHORD Conference, 'New Directions in the History of Retailing and Distribution', 10 September, University of Wolverhampton, UK.

Strasser, S. (2002), "Making consumption conspicuous. Transgressive topics go mainstream", Technology and Culture, Vol. 43 No. 4, pp. 755-770.

Vargo, S.L. and Lusch, R.F. (2004), "Evolving to a new dominant logic for marketing", Journal of Marketing, Vol. 68 No. 1, pp. 1-17.

Vargo, S.L. and Lusch, R.F. (2008), "Service-dominant logic: continuing the evolution”, Journal of the Academy of Marketing Science, Vol. 36 No. 1, pp. $1-10$.

\section{About the author}

Andrew Alexander is Reader in Retail Management at the University of Surrey. His research interests include retail history, the marketing and management of retail locations, and consumer behaviour. His publications on various aspects of the history of retailing and consumption have appeared in Business History, Environment and Planning A, Enterprise \& Society, Journal of Macromarketing and the Journal of Consumer Culture, among others. He is on the Editorial Advisory Board of the Journal of Historical Research in Marketing. 